\title{
Interactive comment on "Evaluating the physical and biogeochemical state of the global ocean component of UKESM1 in CMIP6 Historical simulations" by Andrew Yool et al.
}

Andrew Yool et al.

axy@noc.ac.uk

Received and published: 5 March 2021

Please refer to the attached supplement for our response to our referee

Please also note the supplement to this comment:

https://gmd.copernicus.org/preprints/gmd-2020-333/gmd-2020-333-AC2-

supplement.pdf 